MINIREVIEW

\title{
Molecular mechanism of TNF signaling and beyond
}

\author{
Zheng-gang LIU* \\ Cell and Cancer Biology Branch, Center for Cancer Research, National Cancer Institute, NIH, 9000 Rockville Pike Bethesda, \\ MD 20892, USA
}

\begin{abstract}
Tumor necrosis factor (TNF) is a proinflammatory cytokine that plays a critical role in diverse cellular events, including cell proliferation, differentiation and apoptosis. TNF is also involved in many types of diseases. In recent years, the molecular mechanisms of TNF functions have been intensively investigated. Studies from many laboratories have demonstrated that the TNF-mediated diverse biological responses are achieved through activating multiple signaling pathways. Especially the activation of transcription factors NF- $\mathrm{kB}$ and AP-1 plays a critical role in mediating these cellular responses. Several proteins, including FADD, the death domain kinase RIP and the TNF receptor associated factor TRAF2 have been identified as the key effectors of TNF signaling. Recently, we found that the effector molecules of TNF signaling, such as RIP and TRAF2, are also involved in other cellular responses. These finding suggests that RIP and TRAF2 serve a broader role than as just an effector of TNF signaling.
\end{abstract}

Keywords: TNF, ROS, necrosis, apoptosis, JNK.

\section{INTRODUCTION}

The proinflammatory cytokine tumor necrosis factor (TNF) plays an important role in diverse cellular events such as septic shock, induction of other cytokines, cell proliferation, differentiation, necrosis and apoptosis [1, 2]. TNF is also involved in many diseases including malaria, AIDS and cancer. TNF was originally identified as a factor that leads to rapid hemorrhagic necrosis of transplantable tumors in mice[3]. Approximately one third of trasnformed cell lines were shown to be susceptible to the cytolytic action of TNF [4]. However, because of its toxicity in animals and human, TNF did not fulfill the initial expectations that it would be useful in the treatment of cancer [5]. Many of the TNF-induced cellular responses are mediated by either one of the two TNF receptors, TNF-R1 and TNF-R2, both of which belong to the TNF receptor super-family [6]. In response to TNF treatment, the transcription factor $\mathrm{NF}-\kappa \mathrm{B}$ and MAP kinases, including ERK, p38 and JNK, are activated in most types of cells and, in some cases, apoptosis or necrosis could also be induced $[7,8]$. However, induction

*Correspondence: Zheng-gang LIU

E-mail: zgliu@helix.nih.gov of apoptosis or necrosis is mainly achieved through TNF$\mathrm{R} 1$, which is also known as a death receptor [9]. Activation of the NF- $\kappa \mathrm{B}$ and MAPKs plays an important role in the induction of many cytokines and immune-regulatory proteins and is pivotal for many inflammatory responses $[8,10]$.

The molecular mechanisms that regulate TNF-mediated responses have been intensively studied in recent years. For TNF-R1 signaling, it is known that the binding of TNF to TNF-R1 leads to the recruitment of TRADD (TNF-R1associated death domain protein) into the receptor complex [11]. TRADD subsequently recruits other effector proteins into the complex. FADD/MORT1 (FAS-associated death domain protein), TRAF2 (TNF receptor associated factor 2), and the death domain kinase RIP (receptor interacting protein) have been shown to interact directly with TRADD [12-16]. While FADD/MORT1 is essential for TNF-induced apoptosis through activating a caspase cascade, RIP and TRAF2 are critical in the activation of NF- $\kappa \mathrm{B}$ and JNK [17-20]. We recently reported that both RIP and TRAF2 are also required for the activation of all three types of MAPKs [21]. In addition, it has been reported that RIP mediates TNF-induced necrotic cell death [22]. On the other hand, For TNF-R2 signaling, it is known that the occupancy of TNF-R2 by TNF leads to the recruitment of TRAF1 and TRAF2 as well as cIAP1 and 
cIAP2 [23]. However, because most of the research effort from many laboratories is devoted to the study of TNF-R1 signaling, it is less clear how these molecules correlate to transduce the diverse TNF signals through TNF-R2.

\section{THE RECEPTOR INTERACTING PROTEIN (RIP) PLAYS AN ESSENTIAL ROLE IN DNA DAMAGE-INDUCED NF-KB ACTIVATION}

Cells are often under genotoxic stress, both endogenously (e.g., reactive oxygen species) and exogenously (e.g., ultraviolet radiation, ionizing radiation, and DNAdamaging chemicals). The cellular responses to genotoxic stress include damage sensing, activation of different signaling pathways, and biological consequences such as cell cycle arrest and apoptosis. Tremendous work has been done to investigate the mechanisms that control the cellular responses to genotoxic stress [24]. Transcription factors $\mathrm{p} 53$, activating protein 1 (AP-1), and nuclear factor $\mathrm{B}$ $(\mathrm{NF}-\kappa \mathrm{B})$ have been suggested to play critical roles in mediating cellular responses to genotoxic responses [25, 26]. These transcription factors elicit various biological responses by inducing expression of their target genes.

Because activation of AP-1 and NF- $\kappa$ B can have antiapoptotic or pro-apoptotic effects, the engagement of these two pathways may be key cellular responses that modulate the outcome of cells exposed to radiation and genotoxic drugs. For instance, the ataxia-telangiectasia mutation gene (ATM) has been reported to play an essential role in genotoxic drug-induced activation of $\mathrm{NF}-\kappa \mathrm{B}$, which has a known role in chemoresistance [27, 28]. Although ATM may be critical for sensing DNA damage and subsequently triggering cytoplasmic signaling cascades that lead to NF$\kappa \mathrm{B}$ activation, how the signal is transduced from nucleus to cytoplasm and how the cytoplasmic signaling cascades are initiated are largely unknown. In most types of cells, inactive $\mathrm{NF}-\kappa \mathrm{B}$ is sequestered in the cytoplasm through its interaction with the inhibitory proteins known as IBs. In response to various stimuli, such as the pro-inflammatory cytokines tumor necrosis factor (TNF) and interleukin 1 (IL-1), IBs are phosphorylated by their kinase, IKK, and are rapidly degraded by the proteasome after polyubiquitination. Degradation of IBs leads to the release of NF$\kappa \mathrm{B}$ and allows its translocation into the nucleus and the subsequent activation of its target genes [29].

For TNF-induced IKK and NF- $\kappa$ B activation, two TNF effector molecules are essential, the death domain kinase receptor interacting protein (RIP) and TRAF2. In response to TNF treatment, IKK is recruited to the TNF receptor complex through TRAF2, and its activation requires RIP. RIP interacts with the IKK complex through the regulatory subunit IKK — apparently this interaction also requires TRAF2.

Ionizing radiation and short-wavelength ultraviolet radiation activate $\mathrm{NF}-\kappa \mathrm{B}$ through distinct pathways [30, $31]$. Ultraviolet radiation activates $N F-\kappa B$ through an IKKindependent pathway. For ionizing radiation and genotoxic drugs, DNA damage has been proposed to trigger a cytoplasmic signaling cascade, including IKK activation, to mediate NF- $\kappa B$ activation. However, the signaling components upstream of IKK have not been identified. Previous studies had implied that ultraviolet radiation and genotoxic drugs may activate NF- $\mathrm{NB}$ through cell membrane receptors (e.g., TNF and IL-1 receptors). Thus, it is important to determine whether RIP is involved in NF- $\kappa \mathrm{B}$ activation by ultraviolet radiation or genotoxic drugs.

We found that RIP is essential for NF- $\kappa$ B activation by genotoxic drugs and IR but not by ultraviolet radiation [32]. In wild-type mouse embryonic fibroblasts, DNA damage by agents such as adriamycin, campthothecin, and ionizing radiation induced $\mathrm{NF}-\kappa \mathrm{B}$ activation. In contrast, $\mathrm{NF}-\kappa \mathrm{B}$ activation could not be detected in $R I P^{-/-}$fibroblasts treated with these agents. NF- $\kappa \mathrm{B}$ activation by IL-1 and lipopolysaccharide treatment was normal in $\mathrm{RIP}^{-/-}$ fibroblasts when compared with wild-type fibroblasts. To test whether TNF receptor or other TNF signaling effector molecules (e.g., TRAF2, FADD, and TRAF5) are involved in DNA damage-induced NF- $\kappa \mathrm{B}$ activation, we examined NF- $\kappa \mathrm{B}$ activation in $T N F-R 1^{-/-}, T R A F 2^{-/}, T R A F 5^{--}$, and $F A D D^{-/-}$fibroblasts and found that NF- $\kappa \mathrm{B}$ was activated normally in those cells. Therefore, the involvement of RIP in DNA damage-induced NF- $\kappa \mathrm{B}$ activation is independent of TNF signaling.

Because IKK forms a complex with RIP after DNA damage, RIP may activate IKK through the same mechanism in response to both TNF and DNA damage. However, how RIP senses the signal triggered by DNA damage is still unclear. Since RIP is not a nucleocytoplasmic shuttling protein, one possibility is that, in response to DNA damage, some nuclear proteins are exported into the cytoplasm and interact with RIP to form signaling complexes with IKK. Nevertheless, our work suggests a novel mechanism for the initiation of the cytoplasmic signaling to activate $\mathrm{NF}-\kappa \mathrm{B}$ in response to DNA damage.

\section{A NOVEL SIGNALING PATHWAY CONTROLLING OXIDATIVE STRESS-MEDIATED CELL DEATH}

Oxidative stress refers to the imbalance with enhanced production of reactive oxygen species (ROS) and/or impaired function of the antioxidant system [33]. ROS including superoxide anion, hydroxyl radicals and hydrogen peroxide $\left(\mathrm{H}_{2} \mathrm{O}_{2}\right)$ are known to be important in various biological and pathological processes such as aging, 
inflammation, carcinogenesis, and in the pathogenesis of many human diseases such as neural degenerative diseases, AIDS, and cancer [34, 35]. One important aspect of ROS biological effects is their regulatory roles in cell death. ROS can act either as direct inducers or as signaling molecules in the cell death process triggered by many other stimuli, while the exact molecular targets of ROS and the signaling pathway controlling oxidative stress-mediated cell death are largely elusive $[36,37]$. Previous understanding on the ROS or oxidative stress-related cytotoxicity is mainly based on its adverse effect on cell membrane (membrane lipid peroxidation) or on mitochondria (both functional and structure alteration).

We recently reported that ROS utilize some key cell signaling molecules of TNF signaling, such as RIP, TRAF2 and JNK, to control the life and death of the cell [38]. Such findings will help to elucidate the importance of ROS and oxidative in various physiological and pathological conditions. We found that $\mathrm{H}_{2} \mathrm{O}_{2}$ caused evident cell death in mouse embryonic fibroblast (MEF) in a caspase-independent manner. Interestingly, MEF cells in which the expression of RIP and TRAF2 genes was knocked out are much more resistant to $\mathrm{H}_{2} \mathrm{O}_{2}$-induced cell death than the wild-type (wt) MEF cells. Moreover, the reconstitution of RIP and TRAF2 expression in their respective gene knockout cells significantly restored the sensitivity of the cells to $\mathrm{H}_{2} \mathrm{O}_{2}$, suggesting that RIP and TRAF2 are required for $\mathrm{H}_{2} \mathrm{O}_{2}$-induced cell death. RIP and TRAF2 are two key effector molecules in the TNF signaling pathway and mainly act as cell survival factors to protect against TNF-induced apoptosis via NF- $\kappa \mathrm{B}$ activation. However, a recent report that RIP is required for death receptor-mediated caspase-independent cell death implies that RIP may also act as transducers for cell death signals. Moreover, we found that $\mathrm{H}_{2} \mathrm{O}_{2}$-induced cell death is independent of TNF receptor 1 (TNFR1), as $T N F R 1^{-/-} \mathrm{MEF}$ cells were as sensitive as wt cells to $\mathrm{H}_{2} \mathrm{O}_{2}$-induced cell death. In addition, blockage of de novo protein synthesis failed to affect $\mathrm{H}_{2} \mathrm{O}_{2-}$ induced cell death.

We also found that RIP and TRAF2 form a complex in response to $\mathrm{H}_{2} \mathrm{O}_{2}$ treatment. Using the co-immunoprecipitation technique, a rapid and transient interaction between RIP and TRAF2 was detected upon $\mathrm{H}_{2} \mathrm{O}_{2}$ exposure, and this interaction was independent of TNFR1 and TNFR1-associated death domain (TRADD), another critical molecule in the TNF signaling pathway. Recently, membrane lipid rafts have been implicated in cell signaling. We found that $\mathrm{H}_{2} \mathrm{O}_{2}$ rapidly induced the clustering of FITClabeled cholera toxin $\mathrm{B}$, a marker for membrane lipid rafts, followed by RIP and lipid raft co-localization. Therefore, we believe that a RIP and TRAF2 interaction is an upstream event that initiates the cell death pathway, a pro- cess likely involving membrane lipid rafts and recruitment of some key signaling molecules. Lastly, we identified c-Jun N-terminal kinase (JNK) as the effector molecule in $\mathrm{H}_{2} \mathrm{O}_{2}$-induced cell death downstream of RIP and TRAF2. JNK is a member of the mitogen-activated protein kinase family that plays pivotal roles in cellular responses to stress induced, caspase-independent cell death.

In summary, our study uncovers a novel signaling pathway regulating oxidative stress or ROS-induced cell death, a process involving RIP, TRAF2, and JNK1. It appears that RIP and TRAF2 have critical functions in a much broader spectrum of signal transduction pathways than original thought and act as the convergence point to relay different stimuli or stressors to different downstream signaling pathways that determine life and death of the cell.

\section{REFERENCES}

1 Rothe J, Gehr G, Loetscher H, Lesslauer W. Tumor necrosis factor receptors: structure and function. Immunol Res 1992; 11: 81-90.

2 Tracey KJ, Cerami A. Tumor necrosis factor, other cytokines and disease. Annu Rev Cell Biol 1993; 9:317-43.

3 Carswell EA, Old LJ, Kassel RL, et al. An endotoxin-induced serum factor that causes necrosis of tumors. Proc Natl Acad Sci U S A 1975; 72:3666-70.

4 Sugarman BJ, Aggarwal BB, Hass PE, et al. Recombinant human tumor necrosis factor-alpha: effects on proliferation of normal and transformed cells in vitro. Science 1985; 230:943-5.

5 Beutler B, Cerami A. Tumor necrosis, cachexia, shock, and inflammation: A common mediator. Ann Rev Biochem 1988; 57: 505-18.

6 Tartaglia LA, Goeddel DV. Two TNF receptors. Immunol Today 1992; 13:51-3.

7 Smith CA, Farrah T, Goodwin RG. The TNF Receptor superfamily of cellular and viral proteins : activation, costimulation and death. Cell 1994; 76:59-62.

8 Liu ZG, Han J. Cellular responses to Tumor Necrosis Factor (TNF). Current Issues in Molecular Biology 2001; 3:79-90.

9 Nagata S. Apoptosis by death factor. Cell 1997; 88:355-65.

10 Baeuerle PA, Baltimore D. NF-kappa B: ten years after. Cell 1996; 87:13-20.

11 Hsu H, Xiong J, Goeddel DV. The TNF receptor 1-associated protein TRADD signals cell death and NF-kappa B activation. Cell 1995; 81:495-504.

12 Chinnaiyan AM, O'Rourke K, Tewari M, Dixit VM. FADD, a novel death domain-containing protein, interacts with the death domain of Fas and initiates apoptosis. Cell 1995; 81:505-12.

13 Hsu H, Shu HB, Pan MP, Goeddel DV. TRADD-TRAF2 and TRADD-FADD interactions define two distinct TNF receptor1 signal transduction pathways. Cell 1996; 84:299-308.

14 Hsu H, Huang J, Shu HB, Baichwal V, Goeddel DV. TNFdependent recruitment of the protein kinase RIP to the TNF receptor-1 signaling complex. Immunity 1996; 4:387-96.

15 Rothe M, Wong SC, Henzel WJ, Goeddel DV. A novel family of putative signal transducers associated with the cytoplasmic domain of the $75 \mathrm{kDa}$ tumor necrosis factor receptor. Cell 1994; 78:681-92. 
16 Stanger BZ, Leder P, Lee TH, Kim E, Seed B. RIP: a novel protein containing a death domain that interacts with Fas/APO-1 (CD95) in yeast and causes cell death. Cell 1995; 81:513-23.

17 Liu ZG, Hsu H, Goeddel DV, Karin M. Dissection of TNF receptor 1 effector functions: JNK activation is not linked to apoptosis while NF-kappa B activation prevents cell death. Cell 1996; 87:565-76.

18 Yeh WC, Shahinian A, Speiser D, et al. Early lethality, functional NF-kappaB activation, and increased sensitivity to TNF-induced cell death in TRAF2-deficient mice. Immunity 1997; 7:715-25.

19 Zhang J, Cado D, Chen A, Kabra NH, Winoto A. Fas-mediated apoptosis and activation-induced T-cell proliferation are defective in mice lacking FADD/Mort1. Nature 1998; 392:296-300.

20 Kelliher MA, Grimm S, Ishida Y, et al. The death domain kinase RIP mediates the TNF-induced NF-kappaB signal. Immunity 1998; 8:297-303.

21 Devin A, Lin Y, Liu ZG. The role of the death domain kinase RIP in tumor-nerosis-factor-induced activation of mitogen-activated protein kinases. EMBO reports 2003; 4:623-7.

22 Holler N, Zaru R, Micheau O, et al. Fas triggers an alternative, caspase-8-independent cell death pathway using the kinase RIP as effector molecule. Nat Immunol 2000; 1:489-95.

23 Rothe M, Pan MG, Henzel WJ, Ayres TM, Goeddel DV. The TNFR2-TRAF signaling complex contains two novel proteins related to baculovirus inhibitor or apoptosis proteins. Cell 1995; 83:1243-52.

24 Yang J, Yu Y, Duerksen-Hughes PJ. Protein kinases and their involvement in the cellular responses to genotoxic stress. Mutation. Research 2003; 543:31-58.

25 Pearce A, Humphrey TC. Integrating stress-response and cell cycle checkpoint pathways. Trends in Cell Biol 2001; 11:426-33.

26 Canman CE, Kastan MB. Signal transduction. Three paths to stress relief. Nature 1996; 384:213-4.

27 Shiloh Y. ATM and ATR: networking cellular responses to DNA damage. Curr Opin in Genet Dev 2001; 11:71-7.

28 Boland MP. DNA damage signalling and NF-kappaB: implications for survival and death in mammalian cells. Biochem Soc Trans 2001; 29:674-8.

29 Mayo MW, Baldwin AS. The transcription factor NF-kappaB: control of oncogenesis and cancer therapy resistance. Biochim Biophys Acta 2000; 1470:M55-62.

30 Devary Y, Rosette C, DiDonato JA, Karin M. NF-kappa B activation by ultraviolet light not dependent on a nuclear signal. Science 1993; 261:1442-5.

31 Bender K, Gottlicher M, Whiteside S, Rahmsdorf HJ, Herrlich $P$. Sequential DNA damage-independent and -dependent activation of NF-kappaB by UV. EMBO J 1998; 17:5170-81.

32 Hur GM, Lewis J, Yang Q, et al. The Death Domain Kinase RIP Plays an Essential Role in DNA Damage-induced NF-kappa B Activation. Genes Dev 2003; 17:873-82.

33 Sies H. Oxidative stress: oxidants and antioxidants. Exp Physiol 1997; 82:291-5.

34 Droge W. Free radicals in the physiological control of cell function. Physiol Rev 2002; 82:47-95.

35 Halliwell B. Free radicals, antioxidants, and human disease: curiosity, cause, or consequence? Lancet 1994; 344:721-4.

36 Benhar M, Engelberg D, Levitzki A. ROS, stress-activated kinases and stress signaling in cancer. EMBO Rep 2002; 3: 420-5.

37 Garg AK, Aggarwal BB. Reactive oxygen intermediates in TNF signaling. Mol Immunol 2002; 39:509-17.

38 Shen HM, Lin Y, Choksi S, et al. Essential roles of receptorinteracting protein and TRAF2 in oxidative stress-induced cell death. Mol Cell Biol 2004; 24:5914-22. 